\title{
Literature ReVIEW Efficacy of music therapy in the neuropsychiatric symptoms of dementia: systematic review
}

\author{
Eficácia da musicoterapia nos sintomas neuropsiquiátricos \\ da demência: revisão sistemática \\ Mariângela Aparecida Rezende Aleixo', Raquel Luiza Santos', Marcia Cristina do Nascimento Dourado
}

\section{Keywords}

Music therapy, dementia, neuropsychiatric symptoms.

\section{ABSTRACT}

Objective: A large number of psychosocial interventions in dementia are based on music activities and music therapy interventions. We aim at assessing the efficacy of music therapy in the neuropsychiatric symptoms of people with dementia. Methods: This systematic review is according to the methodology suggested by the Preferred Reporting Items for Systematic Reviews and Meta-Analyses. We searched for articles in PubMed, Web of Knowledge Cross Search, Cochrane Library, Scopus and Lilacs/Bireme databases published from 2005 to 2016. The search keywords included "early onset" and "late onset" combined with "dementia", "Alzheimer", "vascular dementia", "mixed dementia", "frontotemporal dementia", "neuropsychiatric symptoms", "behavioral disturbances", "behavioral and psychological symptoms of dementia" and "music therapy". The studies were categorized according to its efficacy on the decline of neuropsychiatric symptoms and improvement of cognitive function, quality of life and well-being. Results: We selected 12 out of 257 papers. Music therapy interventions were applied individually or in group setting, using active or receptive technique. In general, studies indicated the efficacy of music therapy on the decline of depression, agitation and anxiety. There were heterogeneity of interventions, methodological design and instruments of evaluation among the studies. Conclusions: Although there are reports of the efficacy of music therapy on the decline of neuropsychiatric symptoms of dementia, the area still needs randomized studies aimed at the solution of important methodological problems like the lack of standardized approaches.

\section{RESUMO}

Objetivo: Muitas intervenções psicossociais na demência estão baseadas em atividades musicais e intervenções de musicoterapia. Nosso objetivo consiste em avaliar a eficácia das intervenções de musicoterapia nos sintomas neuropsiquiátricos de pessoas com demência. Métodos: Esta revisão sistemática está de acordo com a metodologia sugerida pela Preferred Reporting Items for Systematic Reviews and Meta-Analyses. Foi realizada busca por artigos nas bases de dados PubMed, Web of Knowledge Cross Search, Cochrane Library, Scopus e Lilacs/Bireme publicados de 2005 a 2016. As palavras-chave incluíram descritores como "início precoce" e "início tardio" combinados com "demência", "Alzheimer", "demência vascular", "demência mista", "demência frontotemporal", "sintomas neuropsiquiátricos", "distúrbios com-

1 Universidade Federal do Rio de Janeiro (UFRJ), Institute of Psychiatry, Center for Alzheimer's Disease and Related Disorders.
Received on
9/22/2016
Approved on
$3 / 14 / 2017$

Address for correspondence: Mariângela Aparecida Rezende Aleixo Av. Venceslau Bras, 71-fundos 22290-140 - Rio de Janeiro, RJ - Brazil Telephone: +55 (21) 99967-0343

E-mail: maraleixo@gmail.com 


\section{Palavras-chave}

Musicoterapia, demência, sintomas neuropsiquiátricos. portamentais", "sintomas comportamentais e psicológicos da demência", "musicoterapia". Os estudos foram categorizados segundo sua eficácia na redução dos sintomas neuropsiquiátricos e na melhora da função cognitiva, qualidade de vida e bem-estar. Resultados: Foram selecionados 12 dos 257 artigos encontrados. As intervenções de musicoterapia foram aplicadas individualmente ou em grupo, utilizando técnica ativa ou receptiva. Em geral, os estudos indicaram a eficácia da musicoterapia na diminuição da depressão, agitação e ansiedade. Houve heterogeneidade das intervenções, desenho metodológico e instrumentos de avaliação entre os estudos. Conclusões: Embora haja relatos de eficácia da musicoterapia na diminuição dos sintomas neuropsiquiátricos da demência, a área ainda necessita de estudos randomizados que visem à solução de problemas metodológicos importantes, como a falta de abordagens padronizadas.

\section{INTRODUCTION}

Dementia involves development of multiple cognitive and functional deficits'. Moreover, the cognitive and neuropsychiatric symptoms can lead to suffering for people with dementia (PwD) and their caregivers ${ }^{2}$. The advance in the pharmacological knowledge has enabled the stabilization and improvement of symptomatology on cognitive and behavioral functions ${ }^{3}$. The current pharmacological treatments are efficacious among mild and moderate PwD and show significant statistical results. However, a combination of pharmacologic treatments and nonpharmacologic approaches is necessary for the appropriate management of the symptoms and disturbances in dementia4. Non-pharmacological interventions aim at improving cognition, expressing emotions, socializing, decreasing agitation and offering guidance to caregivers. They are recommended as initial strategy for behavior disorders and functional decline, and show an important role in delaying the progression of Alzheimer Disease $(A D)^{5}$.

A large number of psychosocial interventions in dementia are based upon music activities and the use of music therapy (MT) interventions has increased over the last decades $^{6}$. According to the World Federation of National Music Therapy ${ }^{7}$, MT is defined as the use of music and/ or its elements (sound, rhythm, melody and harmony) by a qualified music therapist with a client or group. The MT aims to develop potentials and/or restore functions of the individual so that he or she can achieve better intra and/ or interpersonal integration and, consequently, a better quality of life for the prevention, rehabilitation or treatment of diseases. The music therapist uses music parameters such as rhythm and mode, as well as singing, listening and playing instruments, to active or relax, to stimulate cognitive functions and social or emotional well-being, and to reduce anxiety, agitation and depression. In MT, music is focused on musical experience through improvisation, re-creation of music (singing a familiar song and recreating it by changing the rhythm or lyrics), playing musical instruments and musical listening. MT should not be confused with the generalized use of music ${ }^{8}$.

MT can be applied individually or in a group setting, using active or receptive technique. Active MT involves the use of musical instruments, the voice or body, and offers a broad range of opportunities for expression and communication. In the active MT, it is required the presence of a trained music therapist, who needs to have specific expertise at a musical, relational and clinical level. People are invited to play musical instruments or sing with the therapist, either individually or in group. Receptive or passive MT is based on listening to music (LtM), and participants are asked to listen to any genre of music that can be live or recorded. In practice, the music therapist can combine both techniques, and can adapt the method according to disorder ${ }^{6,8}$.

Most studies exploring the benefits and efficacy of MT interventions among PwD are focused on the context of neuropsychiatric symptoms $s^{9-20}$, such as agitation 11,12,18,20, depression ${ }^{10,16}$ or anxiety ${ }^{16,19}$. Other studies are focused on cognitive functions ${ }^{21,22}$, quality of life $(\mathrm{QoL})^{23}$ and wellbeing ${ }^{24}$. Moreover, MT for dementia has frequently been developed without a clear theoretical background or proper evidence from research or clinical practices. In this context, this systematic review aims to analyze the factors related to the efficacy of MT in PwD neuropsychiatric symptoms.

\section{METHODS}

This systematic review is according to the methodology suggested by the Preferred Reporting Items for Systematic Reviews and Meta-Analyses (PRISMA) ${ }^{25}$. We searched for studies about MT in dementia published in Portuguese, English or Spanish from January 2005 to August 2016, using the Web of Knowledge Cross Search (Thomson Scientific/ISI Web Services), PubMed/MEDLINE, Cochrane Library, Scopus and Lilacs/Bireme databases.

The search keywords included "early onset" and "late onset" combined with "dementia", "Alzheimer", "vascular 
dementia", "mixed dementia", "frontotemporal dementia", "neuropsychiatric symptoms", "behavioral disturbances", "behavioral and psychological symptoms of dementia" and "music therapy".

\section{Criteria of inclusion}

We included cross-sectional or longitudinal studies, randomized or nonrandomized, with or without a control group, among people with AD, vascular dementia, mixed or frontotemporal dementia, in all stages of severity. We excluded articles with no casuistic, clinical trials about pharmacologic interventions, studies about MT among people with other pathologies or children, young adults or elderly people without dementia. We also excluded studies developed in mental health institutions, as well as the use of music or other non-pharmacological interventions only with caregivers. The studies were categorized according to its efficacy on the neuropsychiatric symptoms.

\section{Selection of studies}

Two authors independently screened the titles and abstracts to identify eligible papers. We retrieved all possibly relevant articles in full text. We excluded all studies that clearly did not meet all inclusion criteria or that met at least one of the exclusion criteria. Afterwards, two authors independently reviewed the full publications of the remaining papers and had consensus meetings to reach a consensus about inclusion. When necessary, a third co-author of this paper was asked for further information to clarify study eligibility.

\section{Primary outcome}

The primary outcome was reduction in PwD neuropsychiatric problems, depression and anxiety at the end of the intervention.

\section{RESULTS}

We found 257 articles: 46 in PubMed/MEDLINE, 146 in Web of Knowledge Cross Search/ISI, 46 in Cochrane Library, 14 in Scopus, and 5 in Lilacs/BIREME. After the exclusion of redundant cross-references $(\mathrm{N}=55)$ and screening of abstracts, 190 studies were excluded for different reasons. Our sample comprised 12 studies (Table 1).

\section{Design}

Seven out of the 12 studies used a randomized method ${ }^{9-13,16,19}$, and the other trials used various designs such as withinsubject design ${ }^{15}$, controlled trial ${ }^{17}$, a longitudinal repeated measures design with an experimental and control group ${ }^{18}$, crossover study ${ }^{20}$. One study did not mention the method applied $^{14}$

\section{Types of participants}

Elderly with uncategorized dementia9-13, $\mathrm{AD}^{14}$, vascular dementia ${ }^{14,17,20}$, mixed $^{17}$ dementia, in mild ${ }^{16}$, moderate $9,11,13,15,18-20$ and severe $e^{9,11,13,15,18-20}$ stages, male and female, living in nursing ${ }^{9-13,16-19}$ or residential ${ }^{20}$ homes and in treatment in-day center ${ }^{20}$, tertiary hospital ${ }^{14}$ and hospice program $^{15}$.

Table 1. Selection of excluded studies

\begin{tabular}{|c|c|c|}
\hline Domains & Exclusion criteria & Excluded \\
\hline & $\begin{array}{c}N=190 \\
\downarrow\end{array}$ & \\
\hline Study design & $\begin{array}{l}\text { Review, letter, without abstract, other languages, no full version, evaluative tests, without music } \\
\qquad \begin{array}{l}\downarrow \\
N=122\end{array}\end{array}$ & 68 \\
\hline \multirow[t]{2}{*}{ Intervention } & Stimulation with music and/or other modalities no pharmacological, pharmacological treatment, clinical trial of other nature, no clinical trial & 74 \\
\hline & $\begin{array}{l}\text { Music therapy using physiological parameters } \\
\qquad \mathfrak{N}=45\end{array}$ & 3 \\
\hline Participants & $\begin{array}{l}\text { Elderly, other age, familiar/caregivers, other pathologies or matters } \\
\qquad \begin{array}{l}\downarrow \\
N=33\end{array}\end{array}$ & 12 \\
\hline Other matters & $\begin{array}{l}\text { Music, cognition, neuroscience, mental health } \\
\qquad \begin{array}{l}\downarrow \\
N=6\end{array}\end{array}$ & 27 \\
\hline Assistance models & $\begin{array}{l}\text { Elderly with dementia or not } \\
\qquad \begin{array}{l}\downarrow \\
N=0\end{array}\end{array}$ & 6 \\
\hline
\end{tabular}




\section{Type of MT interventions}

The studies showed the use of active group ${ }^{10,12-14,1-20}$, active individual ${ }^{9,11}$, receptive group ${ }^{19}$ and receptive individual9, ${ }^{9,15,16}$ MT interventions.

\section{Instruments}

\section{MT Assessment}

Music Therapy Check List-Dementia (MTCL-D) 9

The MTCL-D'9 is a specific tool derived from a previous general coding scheme: the Music Therapy Check List $(\mathrm{MTCL})^{26}$. This tool is useful for music therapists to monitor and evaluate the music therapeutic process and assesses musical, nonverbal, and verbal behavior. The evaluations are based on analysis of sonorous communication between the music therapist and the PwD. The frequency (occurrences/ minute) and the quality of the interaction between the PwD and the music therapist is measured for each type of behavior: individual production (nonnatuned production, attuned production, variations, listening to music), non verbal behaviors, body engagement, smile, body contact, agitation, anxiety, wandering, aphaty, numbness), verbal behaviors (positive verbalizations, negative verbalizations).

\section{Music Therapy Coding Scheme (MTCS) 17}

The MTCS ${ }^{27}$ is an assessment method using video recordings of MT sessions. This video-based assessment method measuring patient-therapist interaction specifies both affective and behavioral characteristics expressed by the patient and the therapist during a MT session. It consists of four behavioral classes: Verbal Communication, Nonverbal Communication, Countenance, and Sonorous Musical Communication. The first part of the scheme assesses two possible behaviors: 1. Empathetic behavior (EB): the patients actively participate in MT sessions, establishing an empathetic relationship with the music therapist; 2. Nonempathetic behavior (n-EB): both patients and music therapist play musical instruments without establishing an empathetic relationship. The second part of the scheme assesses the level of acceptance of the MT approach, measured by remarking the presence of: Smile: the patient laughs or smiles according to the context. Body movements: the patient moves the body synchronically with the music. Singing: the patient sings during MT session.

\section{Interest in Music Evaluation Form ${ }^{10}$}

The music therapist completed the interest in music evaluation form with each participant before the start of the intervention to collect data on individual musical genre preference (such as classical music, popular music etc.) and previous experience with musical activities and their frequency.

\section{Dementia severity}

Clinical Dementia Rating $(C D R)^{17,20}$

The $\mathrm{CDR}^{28}$ is used to characterize six domains of cognitive and functional performance applicable to Alzheimer disease and related dementias: memory, orientation, judgment and problem solving, community affairs, home and hobbies, and personal care. It is a 5-point scale in which CDR-0 connotes no cognitive impairment, CDR-0.5 = very mild dementia, $\mathrm{CDR}-1=$ mild, $\mathrm{CDR}-2=$ moderate, $\mathrm{CDR}-3=$ severe .

\section{Global Deterioration Scale (GDS) 11,12,18,19}

GDS$^{29}$ provides caregivers an overview of the stages of cognitive function for those suffering from a primary degenerative dementia such as Alzheimer's disease. It is broken down into 7 different stages. Stages 1-3 are the predementia stages. Stages 4-7 are the dementia stages.

\section{Cognition}

Mini-Mental State Examination (MMSE) $10,11,13,14,16-18,20$

The MMSE ${ }^{30}$ assesses cognitive ability within a wide range of domains, including calculation, memory, language, and orientation, with a maximum score of 30 . A score below 23 on the MMSE generally indicates cognitive impairment.

\section{Mental Status Questionnaire (MSQ) ${ }^{18}$}

The $\mathrm{MSQ}^{31}$ provides a brief, objective, and quantitative measurement of cognitive functioning of elderly people. It comprises 10 items with 31 questions which cover spatial and temporal orientation, remote memory, and general knowledge. A score of 0 is ideal; omissions are counted as errors. Three groups of severity of chronic brain syndrome were proposed according to number of errors: 0-2 errors none or minimal; 3-8 errors - moderate; 9 or 10 errors - severe.

\section{Wechsler Adult Intelligence Scale (WAIS) ${ }^{10}$}

WAIS $^{32}$ is used as a general test of intelligence and was developed to assess cognitive ability for adults. This instrument aids in examining the relationship between intellectual function and memory. The test consists of six verbal and five performance subtests. The verbal tests are: Information, Comprehension, Arithmetic, Digit Span, Similarities, and Vocabulary. The Performance subtests are: Picture Arrangement, Picture Completion, Block Design, Object Assembly, and Digit Symbol. A verbal IQ, performance IQ and full scale IQ may be obtained.

\section{Neuropsychiatric symptoms}

Neuropsychiatric Inventory (NPI), 1,1,17,20

The NP| ${ }^{33}$ evaluates 12 common neuropsychiatric disturbances in dementia: delusions, hallucinations, 
agitation, dysphoria, anxiety, apathy, irritability, euphoria, disinhibition, aberrant motor behavior, night-time behavior disturbances, and appetite and eating abnormalities. The severity ( $1=$ mild, $2=$ moderate, $3=$ severe $)$ and frequency ( 1 = occasionally, less than once per week; 2 = often, about once per week; 3 = frequently, several times per week but less than every day; $4=$ very frequently, once or more per day or continuously) of each neuropsychiatric symptom are rated on the basis of scripted questions administered to the patient's caregiver. The total score of these 12 items varies from 0 to 144. Caregiver distress is rated by the caregiver on a six-point scale from 0 (no distress) to 5 (very severe or extreme distress).

\section{Behavioral Pathology in Alzheimer's Disease (BEHAVE-AD) ${ }^{19}$}

BEHAVE-AD ${ }^{34}$ is a 25 -item scale that measures behavioral disturbances in 7 major categories: paranoid and delusional ideation, hallucinations, activity disturbances, aggressiveness, diurnal rhythm disturbance, affective disturbances, anxieties and fobies. Each symptom is scored on a 4-point scale of severity, where $0=$ not present, $1=$ present, $2=$ present, generally with an emotional component, 3 = present, generally with an emotional and physical component. The BEHAVE-AD also contains a 4-point global assessment of the overall magnitude of the behavioral symptoms in terms the disturbance to the caregiver and/or dangerousness to the patient.

Cohen-Mansfield Agitation Inventory (CMAl)1,20 and CMAImodified version ${ }^{12}$

The CMAl 35 assesses 29 agitated behaviors, rated by a proxy caregiver, e.g., pacing, hiding or hoarding things, hitting (including self), repetitive sentences or questions. The 29 items are divided in four subgroups: physical aggressive, physical non-aggressive, verbal aggressive, non-verbal nonaggressive. The frequency of each symptom is rated on a seven-point scale (1-7) ranging from 'never' to 'several times an hour'. Summing all symptom scores reveals a total score that ranges from 29-203.

\section{Revised Memory and Behavioral Problems Checklist (RMBPC) $)^{14}$}

$\mathrm{RMBPC}^{36}$ consists of 24 items scored on a scale of $0-4$ and assesses the occurrence of behavior problems in dementia and their impact on the caregiver using an objective scaling criterion: never occurs (0) to occur daily or more often (4).

\section{Apparent Emotion Scale $(A E S)^{14}$}

$A E S^{37}$ was used to measure changes in the primary outcomes of mood and disruptive behavior. The modified AES, derived from the original Lawton Observed Emotion Rating Scale, was used to measure 6 types of affect in the PWD: pleasure, anger, anxiety, depression, interest/motivation and contentment.
Responses were elicited from the caregiver on how often the PWD expressed a particular emotion in the previous 2 weeks using a Likert scale from 1, denoting 'never', to 5, denoting 'several times a day'. The negative emotions (anger, anxiety and depression) were reverse scored. A summed score was calculated, with higher scores denoting a more positive affect.

\section{Depression and Anxiety}

Cornell Scale for Depression in Dementia (CSDD) and Chinese Version of Cornell Scale for Depression in Dementia (C-CSDD) ${ }^{10}$

The $\mathrm{CSDD}^{38}$ is specially designed for assessing signs and symptoms depression in elderly with dementia. Each item is rated for severity on a scale of $0-2(0=$ absent, $1=$ mild or intermittent, 2 = severe). Scores above 10 indicate a probable major depression. Scores above 18 indicate a definite major depression. Scores below 6 as a rule are associated with absence of significant depressive symptoms.

\section{Hamilton Anxiety scale (HAM-A) ${ }^{16}$}

$\mathrm{HAM}-\mathrm{A}^{39}$ is a scale that consists of 14 items, each defined by a series of symptoms, and measures both psychic anxiety (mental agitation and psychological distress) and somatic anxiety (physical complaints related to anxiety). Each item is scored on a scale of 0 (not present) to 4 (severe), with a total score range of $0-56$, where $<17$ indicates mild severity, $18-$ 24 mild to moderate severity and 25-30 moderate to severe.

\section{Functional capacity}

Barthel Index ${ }^{17}$

Barthel Index ${ }^{40}$ is a 10 -item ordinal scale that measures functional independence in the domains of personal care and mobility in their activities of daily living (ADL): feeding, bathing, grooming, dressing, bowel control, bladder control, toileting, chair transfer, ambulation and stair climbing. The index also indicates the need for assistance in care. The scoring scale ranges from 0 to 100, with 5 point intervals, thus the closer to 100 points the score reached by the individual in the test, the better the functional status. Scores below 50 indicate the dependence of the individual in performing daily living activities.

\section{Quality of life}

Cornell-Brown Scale for Quality of Life in Dementia (CBS-QoL) ${ }^{9}$

The CBS ${ }^{41}$ provides a global assessment of QoL in patients diagnosed with dementia. Some items on the CBS require respondents to indicate if a patient is engaging in more or less of a particular type of behavior. Changes are in reference to the patient's premorbid behavior, prior to the onset of dementia.

\section{Alzheimer's Disease-Related Quality of Life (ADRQL)"}

The ADRQL ${ }^{42}$ consists of 48 items that evaluates five QoL domains: social interaction, awareness of self, feelings and 
mood, enjoyment of activities and response to surroundings. The caregiver answers whether he or she 'agrees' or 'disagrees' to the items. The RMBPC also evaluates the caregiver's reaction to each behavior, thereby providing an index of the impact of each behavior and behavioral domain on the caregiver.

\section{Outcomes}

\section{Neuropsychiatric symptoms $(N=12)^{9-20}$}

Some studies ( $N=8$ ) showed significant difference between the MT group and control group on the reduction of agitation ${ }^{11}$, depression ${ }^{10,16}$, anxiety ${ }^{16,19}$, aggressiveness ${ }^{19}$ and other general behavior disturbances ${ }^{13,19}$. There was also significant improvement on delusions ${ }^{17,20}$, agitation ${ }^{17,20}$, anxiety ${ }^{17,20}$, apathy ${ }^{17,20}$, irritability ${ }^{17,20}$, aberrantmotoractivity ${ }^{17,20}$, night-time disturbances ${ }^{17,20}$, other neuropsychiatric symptom ${ }^{20}$, behavior ${ }^{14}$ and depression ${ }^{14}$. One study showed positive results in eliciting and sustaining participants' alert behavior in the instrumental touch condition ${ }^{15}$. In three studies, there were no significant differences on agitated behaviors ${ }^{12,18}$ and on neuropsychiatric problems $s^{9}$ (Table 2).

\section{DISCUSSION}

In this systematic review, the selected studies focused on the use of MT approaches on neuropsychiatric symptoms.

We observed a considerable heterogeneity of intervention techniques and methods of MT. Interventions were focused on individual active MT $^{9,11}$ or group active $M^{10,12-14,17-20}$, and on individual receptive $M^{9,15,16}$. In the context of dementia, the receptive "relaxation" MT is a method that probably better reduces neuropsychiatric symptoms $s^{16,21}$.

In a multicentric trial, Raglio et al. ${ }^{9}$ showed that behavioral assessment did not show significant differences between active MT and LtM interventions on neuropsychiatric problems in PwD. Participants randomized to MT or LtM participated in 20 individualized 30-minute sessions, twice a week for 10 weeks. During the MT intervention, PwD and music therapist interacted by singing and using melodic and rhythmic instruments (improvisation) to facilitate the expression and modulation of the PwD emotions. In the LtM intervention, PwD listened to music from a preferred playlist and without any interaction with a music therapist or formal caregiver. The music playlist was created by music therapist on the basis of interviews with the PwD and formal or informal caregivers. The larger number of PwD who dropped out in each group and the use of the global NPI score as the primary outcome may have caused the possible non-recognition of the positive effect of music therapy.
A study carried out by Chu et al.10 reported that the MT group significantly reduced depression and improved cognitive function. The music therapist used the Interest in Music Evaluation Form to collect data before the beginning of the intervention (musical preference, prior musical experiences and interest in participating in MT intervention). Two group sessions of 30 minutes per week during 6 weeks used one or more of the following techniques: song choice, music-prompted reminiscence, singing, music listening and instrument playing. The positive effect on depression may be explained by the use of music as a pleasant stimulus focused on familiar songs, which can be relaxing. In turn, in the cognitive functions, the temporal sequence of musical events, the logic of musical form, rhythm and singing may have helped to orient participants. The positive outcome included the use of both subjective and objective measures, careful randomization and follow-up, but the short duration of the intervention and the lack of long-term follow-up were limitations of the study.

Another study ${ }^{11}$ examined the effect of individual MT on agitation of people with moderate/severe dementia living in nursing homes. They used a pragmatic, two-armed, crossover, exploratory randomized controlled study. A total of 12 sessions of individual MT intervention was given twice a week, over a period of 6 weeks and after 6 weeks of standard care. The music therapist should be aware of at least three different ways of applying music in therapy among PwD: a) catching attention and creating a safe setting, b) regulating arousal level to a point where self-regulation is possible and c) engaging the PwD in social communication in order to fulfill psychosocial needs. They reported that agitation disruptiveness increased during standard care and decreased during MT. Results suggested that the effect of MT was greater in Weeks 8-12 than in Weeks 1-6. The improvement in disruptiveness scores during MT was about 8 points in those who received MT later, compared to much smaller improvement in those who received it first.

Moreover, aimed at evaluating immediate short-term effects of MT in reducing agitated behaviors, a randomized controlled trial'12 found a decrease in agitated behaviors in both groups (MT and control), but without a significant difference. Each MT intervention lasted for 40 minutes, twice a week, up to a maximum of 34 sessions. The sessions started with a welcoming song, sung or played by the music therapist (Dutch familiar songs, classical and folk music). The selected music aimed to incite pleasant memories and to reduce agitation, based on musical parameters. The differences in dementia severity between groups suggested better results in MT. However, after adjustment for dementia stage, this trend disappeared completely suggesting that reductions in agitation were due to dementia severity stage instead of the music therapy intervention itself. 
Table 2. Music therapy on the improvement of neuropsychiatric symptoms of dementia $(\mathrm{N}=12)$

\begin{tabular}{|c|c|c|c|c|}
\hline Study/year & Sample & Design & Intervention & Result \\
\hline Raglio et al., $2015^{9}$ & $\begin{array}{l}n=120 \\
\text { dementia moderate/severe }\end{array}$ & Randomized controlled trial & $\begin{array}{l}\text { Individualized } \\
\text { active and receptive } \\
\text { twice a week } \\
30 \text { minutes } \\
10 \text { weeks }\end{array}$ & None behavioral improvement \\
\hline Chu et al., 2014 & $\begin{array}{l}\mathrm{n}=104 \\
\text { dementia }\end{array}$ & $\begin{array}{l}\text { Prospective, permuted-block } \\
\text { randomization }\end{array}$ & $\begin{array}{l}\text { Group active } \\
\text { twice a week } \\
30 \text { minutes } \\
6 \text { weeks }\end{array}$ & $\begin{array}{l}\downarrow \text { Depression } \\
\uparrow \text { Cognitive function }\end{array}$ \\
\hline Ridder et al., 2013"11 & $\begin{array}{l}n=42 \\
\text { dementia, moderate/severe }\end{array}$ & $\begin{array}{l}\text { Pragmatic, crossover, exploratory, } \\
\text { randomized, controlled }\end{array}$ & $\begin{array}{l}\text { Individualized } \\
\text { active } \\
\text { biweekly } \\
30-40 \text { minutes } \\
6 \text { weeks }\end{array}$ & $\downarrow$ Agitation \\
\hline Vink et al., $2013^{12}$ & $\begin{array}{l}\mathrm{n}=77 \\
\text { dementia }\end{array}$ & $\begin{array}{l}\text { Randomized controlled } \\
\text { trial }\end{array}$ & $\begin{array}{l}\text { Group } \\
\text { active } \\
\text { twice a week } \\
40 \text { minutes } \\
4 \text { months }\end{array}$ & None behavior improvement \\
\hline Raglio et al., $2010^{13}$ & $\begin{array}{l}\mathrm{n}=60 \\
\text { dementia severity }\end{array}$ & Randomized controlled & $\begin{array}{l}\text { Group } \\
\text { active } \\
3 \text { times a week } \\
30 \text { minutes } \\
6 \text { months }\end{array}$ & $\downarrow$ Neuropsychiatric symptoms \\
\hline Han et al., $2010^{14}$ & $\begin{array}{l}\mathrm{n}=43 \\
\mathrm{AD} \\
\mathrm{VaD}\end{array}$ & No mention & $\begin{array}{l}\text { Group } \\
\text { active } \\
\text { once a week } \\
2 \text { months }\end{array}$ & $\begin{array}{l}\downarrow \text { Neuropsychiatric symptoms } \\
\downarrow \text { Depression }\end{array}$ \\
\hline Belgrave, $2009^{15}$ & $\begin{array}{l}\mathrm{n}=9 \\
\mathrm{AD} \\
\text { late stage }\end{array}$ & Within-subject design & $\begin{array}{l}\text { Individualized } \\
2 \text { times per week } \\
30 \text { minutes } \\
2 \text { weeks }\end{array}$ & $\begin{array}{l}\text { Alert behavior was more effective } \\
\text { in instrumental touch condition }\end{array}$ \\
\hline Guétin et al., $2009^{16}$ & $\begin{array}{l}\mathrm{n}=30 \\
\mathrm{AD} \\
\text { mild to moderate }\end{array}$ & $\begin{array}{l}\text { Randomized, controlled, } \\
\text { comparative, single-centre }\end{array}$ & $\begin{array}{l}\text { Individualized receptive } \\
\text { once a week } \\
20 \text { minutes } \\
24 \text { months }\end{array}$ & $\begin{array}{l}\downarrow \text { Anxiety } \\
\downarrow \text { Depression }\end{array}$ \\
\hline Raglio et al., $2008^{17}$ & $\begin{array}{l}\mathrm{n}=59 \\
\mathrm{AD}, \\
\mathrm{VaD}, \\
\text { mixed dementia }\end{array}$ & Controlled trial & $\begin{array}{l}\text { Group } \\
\text { active } \\
3 \text { cycles of } 10 \mathrm{MT} \\
30 \text { minutes } \\
16 \text { weeks }\end{array}$ & $\downarrow$ Neuropsychiatric symptoms \\
\hline Ledger and Baker, $2007^{18}$ & $\begin{array}{l}\mathrm{n}=45 \\
\mathrm{AD} \\
\text { moderate/severe }\end{array}$ & $\begin{array}{l}\text { Longitudinal repeated measures } \\
\text { design }\end{array}$ & $\begin{array}{l}\text { Group } \\
\text { active } \\
\text { weekly sessions } \\
30-45 \text { minutes } \\
42 \text { weeks }\end{array}$ & None behavioral improvement \\
\hline Svansdottir and Snaedal, $2006^{19}$ & $\begin{array}{l}\mathrm{n}=38 \\
\mathrm{AD} \\
\text { moderate/severe }\end{array}$ & Randomized controlled trial & $\begin{array}{l}\text { Group } \\
\text { active or receptive } \\
3 \text { times a week } \\
30 \text { minutes } \\
6 \text { weeks }\end{array}$ & $\downarrow$ Neuropsychiatric symptoms \\
\hline Tuet and Lam, $2006^{20}$ & $\begin{array}{l}\mathrm{n}=14 \\
\mathrm{AD} \\
\mathrm{VaD} \\
\text { moderate/severe }\end{array}$ & Crossover study & $\begin{array}{l}\text { Group } \\
\text { active } \\
3 \text { times weekly } \\
45 \text { minutes } \\
6 \text { weeks }\end{array}$ & $\downarrow$ Neuropsychiatric symptoms \\
\hline
\end{tabular}


In addition, regarding people with severe dementia, other randomized controlled trial ${ }^{13}$ suggested a significant difference between groups in reduction of behavioral disturbances. The study was based on three working cycles of 12 MT sessions, with one-month interval of no treatment. The MT approach followed a non-verbal model based on sound-music improvisation. In this model, the interpersonal relationship has great importance and it is considered the core of the intervention. The MT intervention aims at facilitating the moments of harmony that help to organize and regulate the PWD behaviors and emotions. Although the results show significant improvements in MT group, the study presented a limitation in the criteria for randomization that was not standardized. Another limitation was that the NPI global scores were heterogeneous (although not remarkably) at baseline between experimental and control groups, possibly affecting the comparability of the two samples.

Han et al. ${ }^{14}$ explored the effects of a weekly structured MT and activity program on behavioral and depressive symptoms in PwD in a naturalistic setting. The MT integrated a program with other daily activities in a center for people with moderate stage dementia. The music therapist facilitated various music activities for the group, based on the needs and preferences of participants: singing, music and movement, and memory sequences accompanied by music and drumming. The control group did not attend this intervention program, but continued to receive usual care. Disruptive behavior and depression improved in the MT group. Although the study had showed positive results in the MT intervention, there were no evidences about what may really have made an impact in the PwD and how this change may have been effected. However, some limitations should be considered, as the use of a modified version of AES scale. Moreover, the repeated administration of this scale only at the end of the intervention could have resulted in inaccurate caregiver recall about PwD emotions, especially while intervention was carried out. Another limitation was the small sample size, nonrandomized and non-blinded nature of the study.

Belgrave $^{15}$ examined the effect of MT interventions on the behavior of older adults with late-stage Alzheimer's disease. The independent variable in this study was the use of expressive and instrumental touches within the MT sessions. The participants experienced each of the treatment conditions three times: 1) baseline condition (no-touch) the researcher sings to the participant during 15 minutes with no touch; 2) musical condition 1 (expressive touch) the researcher sings to the participant during 15 minutes with a caring touch applied to the shoulder, arm or hand, and then continues singing without applying touch for two measures, 3) musical condition 2 (instrumental touch) - the research sings to the participant during 15 minutes, with instrumental touch, that was defined as a touch used to assist in a completion of a musical task. The study showed that the instrumental touch condition was significantly more effective in eliciting and sustaining participants' alert behavior state. In addition, active and multisensory interventions with PwD should be considered very appropriate in different dementia stages, because it facilitates active participation of PwD even in a severe stage of dementia.

Furthermore, a randomized, controlled comparative, single-centre design ${ }^{16}$, found significant improvements in anxiety and depression in the MT group. Individual receptive MT method was used to reduce anxiety, depression and agitation. The songs were chosen based on the PwD personal tastes following an interview/questionnaire, and a musical sequence was made from the different musical styles suggested (classical music, jazz, world music, various). The music was streamed via headphones in the PwD rooms, and a mask was also offered to avoid visual stimuli and allow concentration on the music. The persistent effect of MT on symptoms of anxiety and depression for up to two months after the end of the sessions was considered as the significant intergroup difference.

Raglio et al. ${ }^{17}$, in a non-verbal MT approach, assessed MT effectiveness in reducing PwD behavioral disturbances. The experimental group participated in MT activities and the control group participated in educational support or entertainment activities. Delusions, agitation, anxiety, apathy, irritability, aberrant motor activity, and night-time disturbances significantly improved in the MT group, but not in the control group. As Guétin et al. ${ }^{16}$, this study observed that the decrease in the neuropsychiatric symptoms occurred in the experimental group and persisted after a month. A limitation of the study was the criteria for randomization which was not standardized. In addition, the assessment for increased communication was done only for the experimental group but not for the control one.

Ledger and Baker ${ }^{18}$ investigated the long-term effects of group MT on agitation. Although MT participants showed short-term reductions in agitation, there were no significant differences between the MT and control groups in the range and frequency of agitated behaviors over time. The range and frequency of agitated behaviors are reflected in the participants' mean total CMAl scores. The multivariate analysis of variance revealed significant effects withinparticipants over time, but not within-participants over time by groups. This result indicated that there were no significant differences between MT and control groups in the range and frequency of agitated behaviors over time.

Svansdottir and Snaedal ${ }^{19}$, in other randomized controlled trial with people with moderately severe and severe $A D$, also found significant reduction in neuropsychiatric disturbances 
in the MT group during a 6-week period, but not in the control group. The PwD could participate actively or passively, and it was possible to include PwD in different stages of severity in the same session. A collection of familiar songs was selected, sung by the music therapist and followed by the group, accompanied by a guitar (music therapist) and various kinds of instruments, according to the PwD choice. This study showed an effect using only one type of music therapy, the active participation of the patient along with the therapist, both with instruments and by singing. The study did not address other music therapy techniques such as passive listening or singing.

Tuet and Lam $^{20}$ in a Chinese PWD sample with agitated behavior suggested significant reductions in the scores of neuropsychiatric symptoms and agitation at the end-music therapy period. In this crossover study, one group received MT and the other usual care with no special intervention. Thereafter, the two groups were crossed over for the further three weeks. Before the beginning of the program, a pilot study was carried out with six patients to identify the suitable piece of music and standardize the logistics of the group session. However, the group sessions in different settings and the non-blinded raters may have contributed to the variability in the way the intervention was implemented and the way subjects respond to the treatment.

In general, the trials indicated the efficacy of MT on neuropsychiatric problems. Some of them showed significant results $11,13,16,17,19,20$ between MT group and control group. Other studies reported non significant ${ }^{9,12,18}$ differences between groups. However, they showed limitations in terms of sample, diagnosis, design, techniques and approaches of MT as well as duration and frequency of interventions. An important issue is related to the MT assessments. They are intersubjective tools which evaluate the therapeutic process and the adherence to the music therapy setting between patient-music therapists. They are not objective and validated measurements. These methodological limitations may be responsible for the controversial results found in the studies. Even with different methodological approaches, MT treatment may be an effective treatment to reduce behavioral disorders in dementia. Further studies should randomize PwD according to the severity of disease in order to better understand the efficacy of MT in the neuropsychiatric symptoms.

\section{CONCLUSION}

Although there are reports of the efficacy of MT in dementia, the evaluated studies showed a considerable heterogeneity of interventions, techniques and methods of MT as well as different methodological designs. Given the heterogeneity of the studies found, it was not possible to assess their effects, taking into account variables such as duration, interval of each intervention and research period, randomized studies with and without a control group, among others. Randomized studies with control group are the best evidence for clinical trials. Our findings suggest more systematic studies, with an adequate clinic protocol, in order to present a more accurate picture of their efficacy.

\section{INDIVIDUAL CONTRIBUTIONS}

Mariângela Aparecida Rezende Aleixo - Performed the literature search and wrote the manuscript.

Raquel Luiza Santos - Independently screened titles and abstracts to identify eligible papers and corrected the article's draft.

Marcia Cristina do Nascimento Dourado Independently screened titles and abstracts to identify eligible papers, guided the conception for the review and the process of performing the literature search, and edited the manuscript.

\section{FINANCIAL SUPPORT}

No competing financial interests.

\section{CONFLICTS OF INTEREST}

No conflicts of interest declared concerning the publication of this article.

\section{ACKNOWLEDGMENTS}

This study was supported by Conselho Nacional de Desenvolvimento Científico e Tecnológico (CNPq), Brazil.

\section{REFERENCES}

1. Americam Psychiatric Association: Diagnostic and Statistical Manual of Mental Disorders. Fifth Edition. Arlington, VA, Americam Psychiatric Association, 2013.

2. Vega U, Marinho V, Tatsch M, Engelhardt E, Laks J. Transtornos de comportamento nas demências: descrição clínica, escalas de avaliação e considerações sobre seu tratamento. In: Bottino CMC, et al. (org). Demência e transtornos cognitivos em idosos. Rio de Janeiro: Guanabara-Koogan; 2006. p. 314-21.

3. Laks J, Engelhardt E. Reports in pharmacological treatments in geriatric psychiatry: is there anything new or just adding to old evidence? Curr Opin Psychiatry. 2008;21(6):562-7.

4. Bottino CMC, Carvalho IAM, Alvarez AMMA, Avila R, Zukauskas PR, Bustamante SEZ, et al. Reabilitação cognitiva em pacientes com doença de Alzheimer. Relato de trabalho em equipe multidisciplinar. Arq Neuropsiquiatr. 2002;60(1):70-9. 
5. Taveira RBR, Taveira DLR, Caixeta L. Abordagens não farmacológicas na doença de Alzheimer. In: Caixeta L, et al. Doença de Alzheimer. Porto Alegre: Artmed; 2012. p. 353-67.

6. Raglio A, Gianelli MV. Music therapy for individuals with dementia: areas of interventions and research perspectives. Curr Alzheimer Res. 2009;6(3):293-301.

7. World Federation National of Music Therapy. Comissão de Prática Clínica. Rev Bras Musicoter. 1996;1(2):4.

8. Bruscia K. Definindo musicoterapia. 2a. Edição. Rio de Janeiro: Enelivros; 2000. p. 332.

9. Raglio A, Bellandi D, Baiardi P, Gianotti M, Ubezio MC, Zanacchi E, et al. Effect of Active Music Therapy and Individualized Listening to Music on Dementia: A Multicenter Randomized Controlled Trial. J Am Geriatr Soc. 2015;63(8):1534-9.

10. Chu H, Yang CH, Lin Y, Ou KL, Lee TY, O'Brien AP, et al. The impact of group music therapy on depression and cognition in elderly persons with dementia: a randomized controlled study. Biol Res Nurs. 2014;16(2):209-17.

11. Ridder HMO, Stige B, Qvale LG, Gold C. Individual music therapy for agitation in dementia: an exploratory randomized controlled trial. Aging Ment Health. 2013;17(6):667-78.

12. Vink AC, Zuidersma M, Boersma F, de Jonge P, Zuidema SU, Slaets JPJ. The effect of music therapy compared with general recreational activities in reducing agitation in people with dementia: a randomized controlled trial Int J Geriatr Psychiatry. 2013;28(10):1031-8.

13. Raglio A, Belleli G, Traficante D, Gianotti M, Ubezio MC, Gentile S, et al. Efficacy of music therapy treatment based on cycles of sessions: a randomized controlled trial Aging Ment Health. 2010;14(8):900-4.

14. Han P, Kwan M, Chen D, Yusoff SZ, Chionh HL, Goh J, et al. A controlled naturalistic study on a weekly music therapy and activity program on disruptive and depressive behaviors in dementia. Dement Geriatr Cogn Disord. 2010;30(6):540-6.

15. Belgrave M. The effect of expressive and instrumental touch on the behavior states of older adults with late-stage dementia of the Alzheimer's type and on music therapist's perceived rapport. J Music Ther. 2009 Summer;46(2):132-46.

16. Guétin S, Portet F, Picot MC, Pommié C, Messaoudi M, Djabelkir L, et al. Effect of music therapy on anxiety and depression in patients with Alzheimer's type dementia: randomized, controlled study. Dement Geriatr Cogn. 2009;28(1):36-46

17. Raglio A, Belleli G, Traficante D, Gianotti M, Ubezio MC, Villani D, et al. Efficacy of music therapy in the treatment of behavioral and psychiatric symptoms of dementia. Alzheimer Dis Assoc Disord. 2008;22(2):158-62.

18. Ledger AJ, Baker FA. An investigation of long-term effects of group music therapy on agitation levels of people with Alzheimer's Disease. Aging Ment Health. 2007;11(3):330-8.

19. Svansdottir HB, Snaedal J. Music therapy in moderate and severe dementia of Alzheimer's type: a case control study. Int Psychogeriatr. 2006;18(4):613-21.

20. Tuet RMW, Lam LCW. A preliminary study of the effects of music therapy on agitation in Chinese patients with dementia. Hong Kong J Psychiatric. 2006;16:87-91.

21. Li CH, Liu CK, Yang YH, Chou MC, Chen CH. Adjunct effect of music therapy on cognition in Alzheimer's disease in Taiwan: a pilot study. Neuropsychiatr Dis Treat. 2015;11:291-6.

22. Bruer RA, Spitznagel E, Cloninger CR. The temporal limits of cognitive change from music therapy in elderly with dementia or dementia-like cognitive impairment: a randomized controlled trial. J Music Ther. 2007;44(4):308-28.

23. Solé C, Mercadal-Brotons M, Galati A, De Castro M. Effects of group music therapy on quality of life, affect, and participation in people with varying levels of dementia. J Music Ther. 2014 Spring;51(1):103-25.
24. Hsu MH, Flowerdew R, Parker M, Fachner J, Odell-Miller H Individual music therapy for managing neuropsychiatric symptoms for people with dementia and their carers: a cluster randomised controlled feasibility study. BMC Geriatr. 2015;15:84.

25. Moher D, Liberati A, Tetzlaff J, Altman DG; PRISMA Group. Preferred reporting items for systematic reviews and meta-analyses: the PRISMA statement. PLOS Med. 2009;6(7):e1000097.

26. Raglio A, Traficante D, Oasi 0. Comparison of the music therapy coding scheme with the music therapy checklist. Psychol Rep. 2007;101(3 Pt 1):875-80.

27. Raglio A, Traficante D, Oasi 0 . A coding scheme for the evaluation of the relationship in music therapy sessions. Psychol Rep. 2006;99(1):85-90.

28. Berg L. Clinical Dementia Rating (CDR). Psychopharmacol Bull. 1988;24(4):637-9.

29. Reisberg B, Ferris SH, de Leon MJ, Crook T. The global deterioration scale for assessment of primary degenerative dementia. Am J Psychiatry. 1982;139(9):1136-9.

30. Folstein MF, Folstein SE, McHugh PR. "Mini-mental state". A practical method for grading the cognitive state of patients for the clinician. J Psychiatr Res. 1975;12(3):189-98.

31. Kahn RL, Goldfarb Al, Pollack M, Peck A. Brief objective measures for the determination of mental status in the aged. Am J Psychiatry. 1960;117:326-8.

32. Wechsler D. The measurement of adult intelligence. Baltimore: Williams \& Wilkins. 1939. p. 229.

33. Cummings IL, Mega M, Gray K, Rosenberg-Thompson S, Carusi DA, Gornbein J. The neuropsychiatric inventory: comprehensive assessment of psyhopathology in dementia. Neurology. 1994;44(12):2308-14.

34. Reisberg B, Auer SR, Monteiro IM. Behavioral pathology in Alzheimer's disease BEHAVE-AD rating scale. Int Psychogeriatr. 1996;8(3):301-8.

35. Cohen-Mansfield J, Marx MS, Rosenthal AS. A description of agitation in a nursing home. J Gerontol. 1989;44:M77-84.

36. Teri L, Truax P, Logsdon R, Uomoto J, Zarit S, Vitaliano PP. Assessment of behavioral problems in dementia: the revised memory and behavior problems checklist. Psychol Aging. 1992;7(4):622-31.

37. Lawton MP, Van Haitsma K, Perkinson M. Observed affect and quality of life in dementia: further affirmations and problems. J Mental Health Aging. 1992;69-81.

38. Alexopoulos GS, Abrams RC, Young RC, Shamoian CA. Cornell Scale for Depression in Dementia. Biol Psychiatry. 1988:23(3):271-84.

39. Hamilton M. The assessment of anxiety states by rating. Br J Med Psychol. 1959;32(1):50-5.

40. Araújo F, Ribeiro JLP, Oliveira A, Pinto C. Validação do índice de Barthel numa amostra de idosos não institucionalizados. Rev Port Sau Pub. 2007;25(2):59-66.

41. Ready RE, Ott BR, Grace J, Fernandez I. The Cornell-Brown Scale for quality of life in dementia. Alzheimer Dis Assoc Disord. 2002;16(2):109-15.

42. Kasper JD, Black BS, Shore AD, Rabins PV. Evaluation of the validity and reliability of the Alzheimer Disease-related Quality of Life Assessment Instrument. Alzheimer Dis Assoc Disord. 2009;23(3):275-84

43. Santos RL, Sousa MFB, Simões-Neto JP, Nogueira ML, Belfort TT, Torres B, et al. Qualidade de vida de cuidadores na demência leve e moderada. Arq Neuro-Psiquiatr. [online]. 2014;72(12):931-7. 